\title{
Trauma Induced Coagulopathy: Prevention and Intervention
}

\section{Jonas P DeMuro* and Adel F Hanna}

Department of Surgery, Division of Trauma and Surgical Critical Care, Winthrop University Hospital, NY, USA

\section{Introduction}

Trauma is associated with 1 in 10 deaths, with approximately 5.8 million mortalities annually worldwide [1]. Significant traumatic bleeding is associated with a poor outcome, with a total mortality of $30 \%$, and is the leading cause of preventable death. Trauma and massive transfusion are associated with trauma induced coagulopathy (TIC), which triggers secondary hypoperfusion, dilutional coagulopathy and dilutional thrombocytopenia, and consumptive coagulopathy of clotting factors and metabolic acidosis, as well as hypothermia, which further enhances this vicious cascade leading to further blood loss. The concept of damage control resuscitation has evolved, which emphasizes early control of bleeding with damage control surgical techniques, early use of blood products with limited crystalloid for resuscitation, and permissive hypotension before hemostasis [2]. While control of the hemorrhage for a bleeding patient must always be the utmost priority, understanding the pathophysiology of TIC, and potential for intervention fosters a more comprehensive approach to this complex phenomenon. Recently, viscoelastic whole blood assay with Thromboelastography (TEG) has been applied to the trauma patient for evaluation in real time of clot strength that can target specific therapies to facilitate hemostatic control.

\section{Etiology}

The etiology of TIC is a trauma that induces significant hemorrhage. With this, a multifactorial cycle is initiated, that further propagates a worsening coagulopathy. Etiological factors for this include the lactic acidosis, tissue injury, hypothermia and dilution from crystalloid resuscitation [3]. Not uncommonly, with the ongoing hemorrhage, and efforts at resuscitation, the TIC becomes progressively worse.

Evidence points to the link between inflammation and coagulopathy following injury. Activation of the coagulation system and the thrombin generated is dependent on intelukleukin-6-expression of tissue factor on activated monocytes and endothelial cells, and tissue factor pathway inhibitors are unable to counteract this effect. Simultaneously, endothelial anticoagulant mechanisms, especially the protein-C system are shut down by proinflmmatory cytokines, at the same time the fibrinolytic system is inactivated resulting in a coagulopathic state.

\section{Massive Transfusion Protocol (MTP)}

Historically, the transfusion for exsanguinating hemorrhage focused on the transfusion of packed red blood cells. In retrospective study, resuscitation with fresh frozen plasma in addition to the packed red blood cells has been shown to have mortality benefit. In military settings, the use of whole blood, which is richer in clotting proteins and platelets, has also been demonstrated to have a benefit; in civilian settings though, the transfusion of whole blood is not available [4].

Furthermore, fresh frozen plasma, which promotes clotting due to the factors present, has the additional benefit of buffering the lactic acidosis. This dual mechanism of action serves to avoid the TIC. Ideally, the packed red blood cell to fresh frozen plasma ratio should be one to one [5]. To achieve this ratio of the various blood products, many institutions have adopted a massive transfusion protocol [6].

\section{Recombinant Factor VIIa}

Recombinant Factor VIIa (rFVIIa) was originally developed as a single clotting factor replacement for the hemophiliac A and B population. More recently, it has been used in cases of refractory TIC to supplement the use of fresh frozen plasma to normalize clotting function [7]. It provides a single clotting protein, and is administered intravenously which has the theoretical advantage of rapid reversal of TIC. While isolated case reports have presented dramatic results, in more rigorous trials, there has not been a mortality benefit shown, although there was a significant reduction in blood transfused in trauma patients after severe blunt trauma $[8,9]$. In addition, concerns remain that the rFVIIa may overpromote thrombosis manifesting as an increase in deep venous thrombosis, pulmonary embolism and myocardial ischemic events.

\section{Prothrombin Complex Concentrate (PCC)}

PCC contains high concentrates of four Vitamin K dependent clotting factors: Factor II, Factor VII, Factor IX and Factor X. Recently, PCC has been utilized for reversal of warfare in patients where vitamin $\mathrm{K}$ and FFP cannot provide a rapid enough reversal as in the setting of significant intracerebral bleeding [10].

PCC has the four factors that are critical for the extrinsic pathway of the clotting cascade, which is disrupted in TIC with endothelial damage. The multifactors in PCC have a theoretical advantage in the reversal of TIC, over what rFVIIa provides, as it more completely repletes the clotting proteins. It should also be noted that there is variability in the contents of PCC under different brands, and that some of the formulations of PCC are only three factors, with no Factor VII, making them less preferred for reversal of TIC [11].

\section{Tranexamic Acid (TXA)}

Hyperfibrinolysis is a contributor to significant coagulopathy, and antifibrinolytic agents can reduce blood loss in patients with an excessive fibrinolytic response to trauma. Tranexamic acid (TXA) is derived from the amino acid lysine that works by the mechanism of blocking the lysine site of plasminogen. TXA has been shown in multiple studies to reduce the need for blood transfusion by a third in elective surgery cases, but did not change the mortality [12]. In the CRASH-2 trial, over 20,000 adult trauma patients were treated with

*Corresponding author: Jonas P DeMuro, Winthrop University Hospital, Department of Surgery, Division of Trauma and Surgical Critical Care 259 First Street, Mineola NY 11501, USA, Tel: 1-516-663-8700; E-mail: jdemuro@winthrop.org

Received January 20, 2014; Accepted January 28, 2014; Published February 02, 2014

Citation: DeMuro JP, Hanna AF (2014) Trauma Induced Coagulopathy: Prevention and Intervention. J Blood Disorders Transf 5: e110. doi: 10.4172/2155-9864.1000e110

Copyright: (c) 2014 DeMuro JP et al. This is an open-access article distributed under the terms of the Creative Commons Attribution License, which permits unrestricted use, distribution, and reproduction in any medium, provided the original author and source are credited. 
Citation: DeMuro JP, Hanna AF (2014) Trauma Induced Coagulopathy: Prevention and Intervention. J Blood Disorders Transf 5: e110. doi: 10.4172/2155-9864.1000e110

tranexamic acid as compared to placebo, and a significant decrease in all cause mortality was noted, without an increase in vascular occlusive events [13].

\section{Thromboelastography (TEG)}

With the ability to provide more rapid resuscitations, and the early use of blood products, specifically platelets, FFP and cryoprecipitate, with potential for augmentation in clotting factors via rFVIIa and/or PCC the need arises to have a rapid assessment of the bleeding patients coagulation system to direct further therapy. Traditional evaluation has included a quantitative platelet count, and the prothrombin and partial thromboplastin time. However, these tests are limited by the laboratory turnaround time, and fail to provide information in real time given this limitation. In addition, there is potential to target the therapy, with a recent series suggesting a mortality benefit in TEG directed massively transfused penetrating trauma patients [14].

Thromboelastography (TEG) has gained popularity in the last several years for monitoring TIC, and guiding therapy of blood products. The attraction is the rapid turnaround time compared to the traditional lab tests. TEG derives its results by analyzing the physical properties of clot formation [15]. Future research will be needed to elucidate the precise role of this technology to the population of TIC.

\section{Conclusion}

TIC remains an important contributor to trauma mortality. With an understanding of the pathophysiology, and the multifactorial contributors to the common pathway of the coagulopathic state, intervention is possible to prevent the coagulopathy from developing, and to stabilize it once it is initiated with the recent advances described.

\section{References}

1. Centers for Disease Control and Prevention (CDC) (2014) CDC Grand Rounds: Evidence-Based Injury Prevention. MMWR Morb Mortal Wkly Rep 62: 1048-1050.

2. Holcomb JB, Jenkins D, Rhee P, Johannigman J, Mahoney P, et al. (2007) Damage control resuscitation: directly addressing the early coagulopathy of trauma. J Trauma 62: 307-310.
3. Johansson PI, Stensballe J, Ostrowski SR (2012) Current management of massive hemorrhage in trauma. Scand J Trauma Resusc Emerg Med 20: 47.

4. Borgman MA, Spinella PC, Perkins JG, Grathwohl KW, Repine T, et al. (2007) The ratio of blood products transfused affects mortality in patients receiving massive transfusions at a combat support hospital. J Trauma 63: 805-813.

5. Brown LM, Aro SO, Cohen MJ (2011)A High Fresh Frozen Plasma: Packed Red Blood Cell Transfusio Ratio Decreases Mortality in All Massively Transfused Trauma Patients Regardless of Admission International Normalized Ratio. $J$ Trauma 71: s358-s363.

6. Riskin DJ, Tsai TC, Riskin L, Hernandez-Boussard T, Purtill M, et al. (2009) Massive transfusion protocols: the role of aggressive resuscitation versus product ratio in mortality reduction. J Am Coll Surg 209: 198-205.

7. Duchesne JC, Mathew KA, Marr AB, Pinsky MR, Barbeau JM, et al. (2008) Current evidence based guidelines for factor VIla use in trauma: the good, the bad, and the ugly. Am Surg 74: 1159-1165.

8. Kenet G, Walden R, Eldad A, Martinowitz U (1999) Treatment of traumatic bleeding with recombinant factor Vlla. Lancet 354: 1879.

9. Boffard KD, Riou B, Warren B, Choong PIT, Rizoli S, et al. (2005) Recombinant Factor VIla as Adjunctive Therapy for Bleeding Control in Severely Injured Trauma Patients: Two Parallel Randomized, Placebo-Controlled, Double-Blind Clinical Trials. Journal of Trauma 59: 8-18.

10. McSwain N Jr, Barbeau J (2011) Potential use of prothrombin complex concentrate in trauma resuscitation. J Trauma 70: S53-56.

11. Frumkin K (2013) Rapid reversal of warfarin-associated hemorrhage in the emergency department by prothrombin complex concentrates. Ann Emerg Med 62: 616-626.

12. Henry DA, Carless PA, Moxey AJ, O'Connell D, McClelland B, et al. (2007) Anti-fibrinolytic use for minimising perioperative allogenic blood transfusion. Cochrane Database Systemic Review.

13. Shakur H, Roberts I, Bautista R, Caballero J, Coats T, et al. (2010) Effects of tranexamic acid on death, vascular occlusive events, and blood transfusion in trauma patients with significant haemorrhage (CRASH-2): a randomised, placebo-controlled trial. Lancet 376: 23-32.

14. Tapia NM, Chang A, Norman M, Welsh F, Scott B, et al. (2013) TEG-guided resuscitation is superior to standardized MTP resuscitation in massively transfused penetrating trauma patients. J Trauma Acute Care Surg 74: 378-385.

15. da Luz LT, Nascimento B, Rizoli S (2013) Thrombelastography (TEG®): practical considerations on its clinical use in trauma resuscitation. Scand $J$ Trauma Resusc Emerg Med 21: 29 